\title{
Three-dimensional finite element model of the drilling process used for fixation of Salter-Harris type-3 fractures by using a K-wire
}

\author{
A. Gok ${ }^{1}$, K. Gok ${ }^{2}$, and M. B. Bilgin ${ }^{1}$ \\ ${ }^{1}$ Amasya University, Technology Faculty, Department of Mechanical Engineering, 05000 Amasya, Turkey \\ ${ }^{2}$ Dumlupınar University, Kütahya Vocational School of Technical Sciences, Germiyan Campus, 43100 \\ Kütahya, Turkey \\ Correspondence to: A. Gok (arif.gok@amasya.edu.tr)
}

Received: 26 December 2014 - Revised: 18 June 2015 - Accepted: 6 July 2015 - Published: 20 August 2015

\begin{abstract}
In this study, the drilling process was performed with Kirschner wire (K-wire) for stabilization after reduction of Salter-Harris (SH) type-3 epiphyseal fractures of distal femur. The study was investigated both experimentally and numerically. The numerical analyses were performed with finite element method (FEM), using DEFORM-3D software. Some conditions such as friction, material model and load and boundary must be identified exactly while using FEM. At the same time, an analytic model and software were developed, which calculate the process parameters such as drilling power and thrust power, heat transfer coefficients and friction coefficient between tool-chip interface in order to identify the temperature distributions occurring in the K-wire and bone model (Keklikolu Plastik San.) material during the drilling process. Experimental results and analysis results have been found as consistent with each other. The main cutting force, thrust force, bone model temperature and K-wire temperature were measured as $80^{\circ} \mathrm{N}, 120^{\circ} \mathrm{N}, 69^{\circ} \mathrm{C}$ and $61^{\circ} \mathrm{C}$ for $400 \mathrm{rpm}$ in experimental studies. The main cutting force, thrust force, bone model temperature and $\mathrm{K}$-wire temperature were measured as $65^{\circ} \mathrm{N}, 87^{\circ} \mathrm{N}, 91^{\circ} \mathrm{C}$ and $82^{\circ} \mathrm{C}$ for $800 \mathrm{rpm}$ in experimental studies. The main cutting force, thrust force, bone model temperature and K-wire temperature were measured as $85^{\circ} \mathrm{N}, 127^{\circ} \mathrm{N}, 72^{\circ} \mathrm{C}$ and $67^{\circ} \mathrm{C}$ for $400 \mathrm{rpm}$ in analysis studies. The main cutting force, thrust force, bone model temperature and $\mathrm{K}$-wire temperature were measured as $69^{\circ} \mathrm{N}, 98^{\circ} \mathrm{N}, 83^{\circ} \mathrm{C}$ and $76^{\circ} \mathrm{C}$ for $800 \mathrm{rpm}$ in analysis studies. A good consistency was obtained between experimental results and finite element analysis (FEA) results. This proved the validity of the software and finite element model. Thus, this model can be used reliably in such drilling processes.
\end{abstract}

\section{Introduction}

A Salter-Harris fracture is a fracture and it involves the epiphyseal plate or growth plate of bone. Salter-Harris fractures are widely seen as an injury type in children, occurring in $15 \%$ of childhood long bone fractures (Salter and Harris, 1963).

Fractures of the distal femur epiphysis have a particularly high risk in terms of growth arrest and other morbidities (Basener et al., 2009; Eid and Hafez, 2002; Mann and Rajmaira, 1990; Peterson et al., 1994). The factors causing this situation are considered to be age, fracture type, degree of displacement, the wavy structure of physics and quality of the fracture reduction (Dahl et al., 2014; Liu et al., 2013; Lombardo and Harvey, 1977). Considering the histology of the situation which is the main cause for angulation and growth complications, physeal bar formation is considered to be the main cause (Dahl et al., 2014; Herring, 2002). In the treatment of Salter-Harris (SH) type-3 epiphysis fractures of distal femur, partially threaded screws are applied in parallel to the articular bone and do not go through the physis line, or Kirschner wires (K-wire) are recommended for fixation (Wheelessonline, 2014; Zionts, 2003). In particular, the technique of fixation with $\mathrm{K}$-wire is widely used.

In our daily lives, any fracture can occur in our musculoskeletal system as a result of any trauma. These fractures 


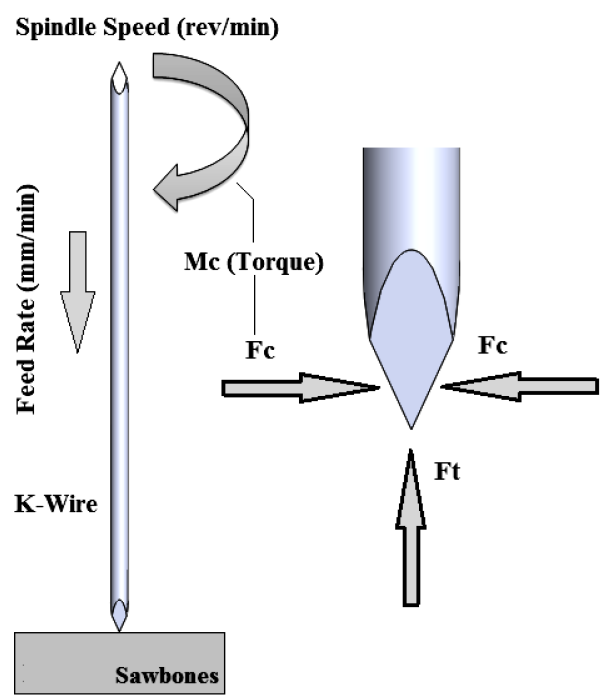

Figure 1. The drilling operation with K-wire and the forces occurring.

are fixed by surgeons using a variety of screws, implants or $\mathrm{K}$-wire. In particular, if the surgeon used a screw to stabilize the fracture, a drill bit suitable for dimensions of the screw would be needed to perform the drilling process. In the literature, bone drilling processes are commonly encountered in order to ensure the broken bone stability. During the drilling process, friction-induced heat emerges due to the temperature difference between drilling tool and bone. This heat results in undesirable thermal damage to the bone and surrounding tissues. The temperature that causes the emergence of heat has a certain critical value. There are many studies on this critical value in the literature. The study by Hillery and Shuaib (1999) showed that the bone undergoes serious damage when the temperature rises above $55^{\circ} \mathrm{C}$ in $30 \mathrm{~s}$. Eriksson et al. (1984) studied in vivo and presented that the cortical bone of a rabbit showed thermal necrosis above $47^{\circ} \mathrm{C}$ in $60 \mathrm{~s}$. Augustin et al. (2008) reported that the temperature could increase above $47^{\circ} \mathrm{C}$, which causes irreversible osteonecrosis during the bone drilling process.

Optimization of drilling parameters is very important especially bone drilling processes in terms of necrosis in bone and soft tissues. This status requires expensive experimental equipment and additional safety measures to protect from biohazards today. Finite element analysis (FEA) of bone drilling may be an important feature in new surgical techniques. Experimental work eliminates equipment costs as well as potential health risks associated with biological materials. Modeling of the bone drilling process using FEA may be useful for validation of experimental or analytical results. It is considered as a reliable tool to develop new surgical techniques (Alam et al., 2010).

Many researchers also simulated the bone drilling process using the computer-aided FEA tool. Surgical drill bit or K-wires are used in many of these studies and are related to temperature occurring in bone or necrosis caused by them. Some studies are related to optimum drilling parameters. Gok et al. (2015a) developed a new driller system to prevent osteonecrosis, and so they performed optimization of bone drilling processing parameters (Gok et al., 2015b). Yuan-Kun $(2008,2009)$ developed an elastic-plastic dynamic FEA tool to simulate the effects of processing parameters on the temperature rise during the bone drilling process in which the drill bit and Kirschner pin are used. YuanKun (2011) proposed an empirical equation to calculate the peak bone temperature caused by the applied force and revolutions per minute and compared the results with the FEA simulations. Sezek et al. (2012) measured the inevitable temperature changes that occurred in orthopaedic drilling and studied them to optimize the drilling parameters within a safe drilling temperature lower than $45^{\circ} \mathrm{C}$. Alam et al. (2009) developed a FEA model of the bone drilling process and compared results with experimental results.

In the literature, there are many available studies analyzed by using FEA in bone drilling processes (Gok et al., 2015a, b). But there are no studies to determine the process parameters like heat transfer coefficient, drilling power or machining power and friction coefficient between tool-chip interfaces, which are very important inputs in numeric simulations. Software, analytic model and finite element method (FEM) calculate these process parameters, having been developed for bone drilling simulations by using K-wire in the study.

\section{Development of the analytic model and software for the drilling process using K-wire}

During the drilling process, moment of rotation occurs due to the rotation and thrust force occurs due to the thrust movement on the drill bit (Fig. 1). The moment of rotation creates the drilling power given in Eq. (1), while thrust force creates the thrust power given in Eq. (2). A large part of the mechanical energy generated during the drilling process is converted into the heat energy given in Eqs. (4) and (5), respectively. Software was developed to calculate the heat transfer coefficient and the thermal conductivity coefficient between bone model, K-wire and ambient using following equations. The software was developed using Visual Basic 6.0 (Fig. 2). In this interface, drilling parameters and heat transfer parameters are input sections. Drilling power, thrust power, total mechanical power, heat transfer between K-wire with bone, heat transfer for K-wire and heat transfer for bone model are 


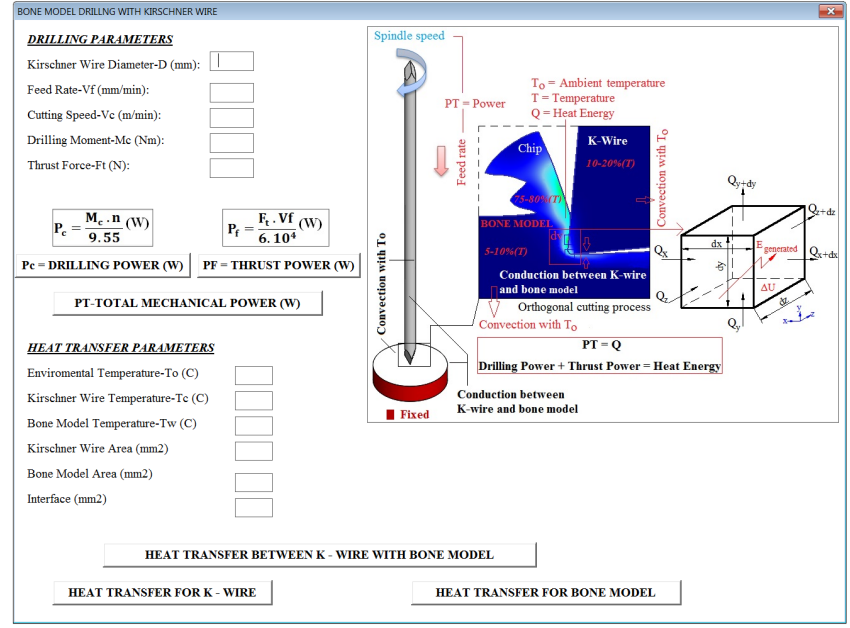

Figure 2. The interface of the developed software.

output sections.

$$
\begin{aligned}
P_{c} & =\frac{M_{c} \cdot n}{9550} \\
P_{f} & =\frac{F_{\mathrm{t}} \cdot V_{\mathrm{f}}}{60 \cdot 1000} \\
\mathrm{PT} & =P_{c}+P_{f}
\end{aligned}
$$

In here, $P_{c}$ is the drilling power, $P_{f}$ is the thrust power, PT is the total power, $n$ is the spindle speed, $M_{c}$ is the torque, $F_{\mathrm{t}}$ is the thrust force, and $V_{\mathrm{f}}$ is the feed rate.

$$
\begin{aligned}
& Q_{\text {convection }}=h_{\mathrm{t}} \cdot A \cdot\left(T-T_{o}\right) \\
& Q_{\text {conduction }}=-k \cdot A \cdot\left(\frac{\partial T}{\partial n}\right)
\end{aligned}
$$

In here, $h_{\mathrm{t}}$ is the heat transfer coefficient for convection, $k$ is the thermal conductivity coefficient for conduction, $A$ is the contact area, $T$ is the bone model or $\mathrm{K}$-wire temperature, $T_{O}$ is the ambient temperature, and $\frac{\partial T}{\partial n}$ is the derivative along the outward drawn normal to the surface.

If conservation of energy law (first law of thermodynamics) is applied to this control volume (Fig. 3), Eq. (6) would be obtained; the general equation of heat conduction in Eq. (7) is also obtained by ignoring the higher terms in Taylor series. By writing the $m$ mass, in the internal energy formula in the right side of the Eq. (25) as in Eq. (26), it is then put into place in Eq. (27).

$$
E_{\text {input }}-E_{\text {output }}+E_{\text {generated }}-E_{\text {convection }}=\Delta U
$$

For the input energy Eq. (6), the input heat amounts in the $x$, $y$, and $z$ axes are shown in Eqs. (7), (8), and (9). The areas in these equations are defined in Eqs. (1), (2) and (3) for $x, y$, and $z$ axes. $k$, in these equations, is heat conduction coefficient. Because of the contact between the workpiece and the drill bit, a heat transfer with conduction occurs.

$$
\begin{aligned}
& Q_{x}=-k \cdot A_{x} \cdot \frac{\partial T}{\partial x} \\
& Q_{y}=-k \cdot A_{y} \cdot \frac{\partial T}{\partial y} \\
& Q_{z}=-k \cdot A_{z} \cdot \frac{\partial T}{\partial y} \\
& A_{x}=\mathrm{d} y \cdot \mathrm{d} z \\
& A_{y}=\mathrm{d} x \cdot \mathrm{d} z \\
& A_{z}=\mathrm{d} x \cdot \mathrm{d} y
\end{aligned}
$$

For the output energies, if, by using Taylor's series expansion $\left(Q_{x+\mathrm{d} x}, Q_{y+\mathrm{d} y}\right.$ and $\left.Q_{z+a z}\right)$, higher-order terms are neglected, Eqs. (13), (14), and (15) are acquired.

$Q_{x+\mathrm{d} x}=Q_{x}+\frac{\partial Q_{x}}{\partial x} \cdot \mathrm{d} x$

$Q_{y+\mathrm{d} y}=Q_{y}+\frac{\partial Q_{y}}{\partial y} \cdot \mathrm{d} y$

$Q_{z+\mathrm{d} z}=Q_{z}+\frac{\partial Q_{z}}{\partial z} \cdot \mathrm{d} z$

The generated energy in the system is written as volumetric in Eq. (4). Equation (18) can be written for the heat transfer with the environment of workpiece and the drill bit. Equation (19) can be written for the collected energy in the system. Here, mass is $m$, specific heat capacity is $c_{p}$, and the control volume is defined as $\mathrm{d} v$.

$E_{\text {generated }}=Q \cdot \mathrm{d} v$

$\mathrm{d} v=\mathrm{d} x \cdot \mathrm{d} y \cdot \mathrm{d} z$

$Q_{\text {convection }}=h_{t} \cdot \mathrm{d} A_{z} \cdot\left(T-T_{o}\right)$

$\Delta U=m \cdot c_{p} \cdot \frac{\partial T}{\partial t}$

Putting these equations above in their places in Eq. (6), the following equations are acquired.

$$
\begin{aligned}
& Q_{x}+Q_{y}+Q_{z}-\left(Q_{x+\mathrm{d} x}+Q_{y+\mathrm{d} y}+Q_{z+\mathrm{d} z}\right)+Q \cdot \mathrm{d} v \\
& -h_{t} A_{z}\left(T-T_{o}\right) \cdot \mathrm{d} z=m \cdot c_{p} \frac{\partial T}{\partial t} \\
& -\frac{\partial}{\partial x}\left(-k \cdot A_{x} \cdot \frac{\partial T}{\partial x}\right) \mathrm{d} x-\frac{\partial}{\partial y}\left(-k \cdot A_{y} \cdot \frac{\partial T}{\partial y}\right) \mathrm{d} y \\
& -\frac{\partial}{\partial z}\left(-k \cdot A_{z} \cdot \frac{\partial T}{\partial z}\right) \mathrm{d} z+Q \\
& \cdot \mathrm{d} v-h_{t} \mathrm{~d} A_{z}\left(T-T_{o}\right) \mathrm{d} z=m \cdot c_{p} \cdot \frac{\partial T}{\partial t}
\end{aligned}
$$




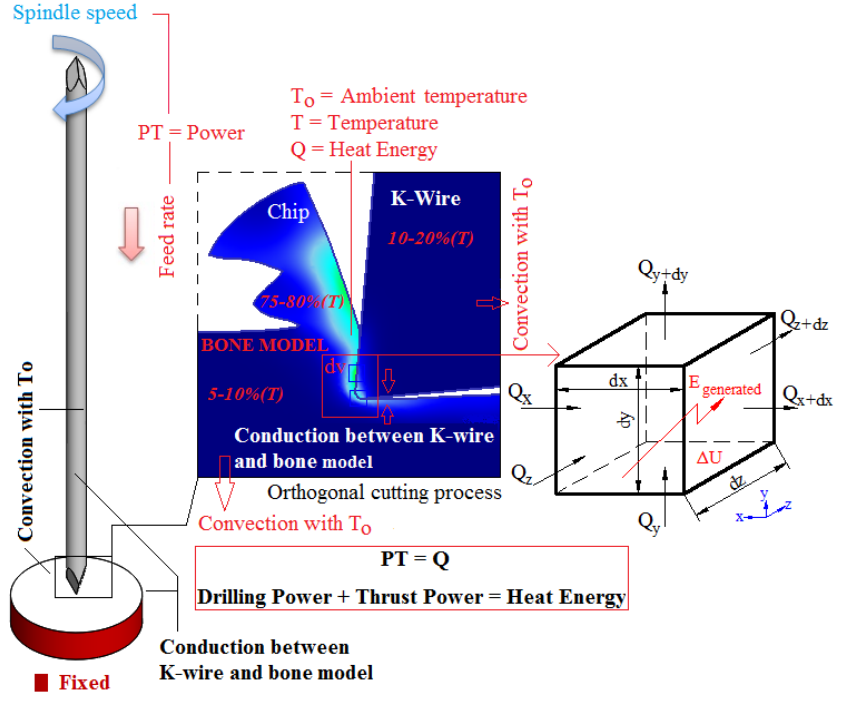

Figure 3. Thermal model of the drilling process using K-wire.

$$
\begin{aligned}
& \frac{\partial^{2} T}{\partial x^{2}} k \cdot A_{x} \cdot \mathrm{d} x+\frac{\partial^{2} T}{\partial y^{2}} k \cdot A_{y} \cdot \mathrm{d} y+\frac{\partial^{2} T}{\partial z^{2}} k \cdot A_{z} \mathrm{~d} z \\
& +Q \cdot \mathrm{d} v-h_{t} \cdot A_{z} \cdot\left(T-T_{o}\right) \cdot \mathrm{d} z=m \cdot c_{p} \cdot \frac{\partial T}{\partial t} \\
& \rho=\frac{m}{\mathrm{~d} v}, m=\rho \cdot \mathrm{d} v \\
& \frac{\partial^{2} T}{\partial x^{2}} \cdot k \cdot \mathrm{d} y \cdot \mathrm{d} z \cdot \mathrm{d} x+\frac{\partial^{2} T}{\partial y^{2}} \cdot k \cdot \mathrm{d} x \cdot \mathrm{d} z \cdot \mathrm{d} y+\frac{\partial^{2} T}{\partial z^{2}} \\
& \cdot k \cdot \mathrm{d} x \cdot \mathrm{d} y \cdot \mathrm{d} z+Q \cdot \mathrm{d} x \cdot \mathrm{d} y \cdot \mathrm{d} z-h_{t} \cdot \mathrm{d} x \cdot \mathrm{d} y \cdot \mathrm{d} z\left(T-T_{o}\right) \\
& =\rho \cdot \mathrm{d} v \cdot c_{p} \frac{\partial T}{\partial t} \\
& \left(\frac{\partial^{2} T}{\partial x^{2}}+\frac{\partial^{2} T}{\partial y^{2}}+\frac{\partial^{2} T}{\partial z^{2}}\right)+\frac{Q}{k}-\frac{h_{t} \cdot\left(T-T_{o}\right)}{k} \\
& =\frac{\rho \cdot c_{p}}{k} \cdot \frac{\partial T}{\partial t}
\end{aligned}
$$

In Eq. (27) the general equation of heat conduction is acquired by writing thermal expansion coefficient, $\alpha$, as in Eq. (26) and Ulutan et al. (2009).

$$
\begin{aligned}
& \alpha=\frac{k}{\rho \cdot c_{p}} \\
& \left(\frac{\partial^{2} T}{\partial x^{2}}+\frac{\partial^{2} T}{\partial y^{2}}+\frac{\partial^{2} T}{\partial z^{2}}\right)+\frac{Q}{k}-\frac{h_{t} \cdot\left(T-T_{o}\right)}{k}=\frac{1}{\alpha} \frac{\partial T}{\partial t}
\end{aligned}
$$

In here, $E_{\text {input }}$ is the input energy to system, $E_{\text {output }}$ is the output energy from system, $E_{\text {generated }}$ is the accumulated in the system energy, $E_{\text {convection }}$ is the output energy from system with convection, $\mathrm{Q}$ is the heat energy, and $\alpha$ is the thermal diffusivity coefficient.
Table 1. Bone model drilling process parameters for simulation model.

\begin{tabular}{lcc}
\hline $\begin{array}{l}\text { Drilling process } \\
\text { parameters }\end{array}$ & \multicolumn{2}{c}{$\begin{array}{c}\text { Spindle speed } \\
(\mathrm{rpm})\end{array}$} \\
\hline & 400 & 800 \\
\hline Drilling power (W) & 2.51 & 4.08 \\
Thrust power (W) & 0.08 & 0.05 \\
Total power (W) & 2.59 & 4.14 \\
Friction coefficient & 0.53 & 0.41 \\
\hline
\end{tabular}

\section{The bone model drilling processes}

A mini $2.5 \mathrm{~kW}$ CNC machine was used for the bone model drilling processes. The drilling processes were performed on bone model samples similar to bone by using a K-wire in $3 \mathrm{~mm}$ diameter (rake angle $-28^{\circ}$ and clearance angle $+6^{\circ}$ ) with spindle speeds of 400 and $800 \mathrm{rpm}$ and feed rate of $40 \mathrm{~mm} \mathrm{~min}^{-1}$. The drilling moment and thrust force which occurred during drilling processes were measured by using a Kistler 9257B dynamometer. Two measurement devices were used for temperature measurements (Fig. 4). While the bone model temperature values were measured using PT100 thermocouple, the $\mathrm{K}$-wire temperature values were measured using non-contact temperature sensor. The PT100 sensor was used to measure the temperature of the bone model sample as illustrated in Fig. 6. As seen, a hole of $6 \mathrm{~mm}$ diameter was prepared by drilling in the bone model to place the thermocouple rod with the distance of $0.5 \mathrm{~mm}$ to the surgical drill bit to measure the bone model temperature levels during the drilling. The distance to place the thermocouple was used about $1 \mathrm{~mm}$ by researchers.

\section{Computer-aided finite element analysis}

The aim of this study was to calculate the thrust power and drilling power as well as heat transfer coefficients required for numerical simulations of bone model drilling processes using a K-wire. DEFORM-3D finite element-based program was used to perform these bone model drilling processes. The 3-D model of K-wire used in the simulations was created by SolidWorks 2013, and 3-D model of the workpiece was modeled by using the Geometry Primitive feature of DEFORM3D software.

\subsection{Loading and boundary conditions}

Firstly, the mesh division for FEA was performed. Tetrahedral element type was selected for the mesh processing. While the mesh structure of bone model consists of 21498 elements and 4853 nodes, the mesh structure of K-wire consists of 22958 elements and 5742 nodes. The mesh structure of bone model and drill bit are given in Fig. 5a. In addi- 


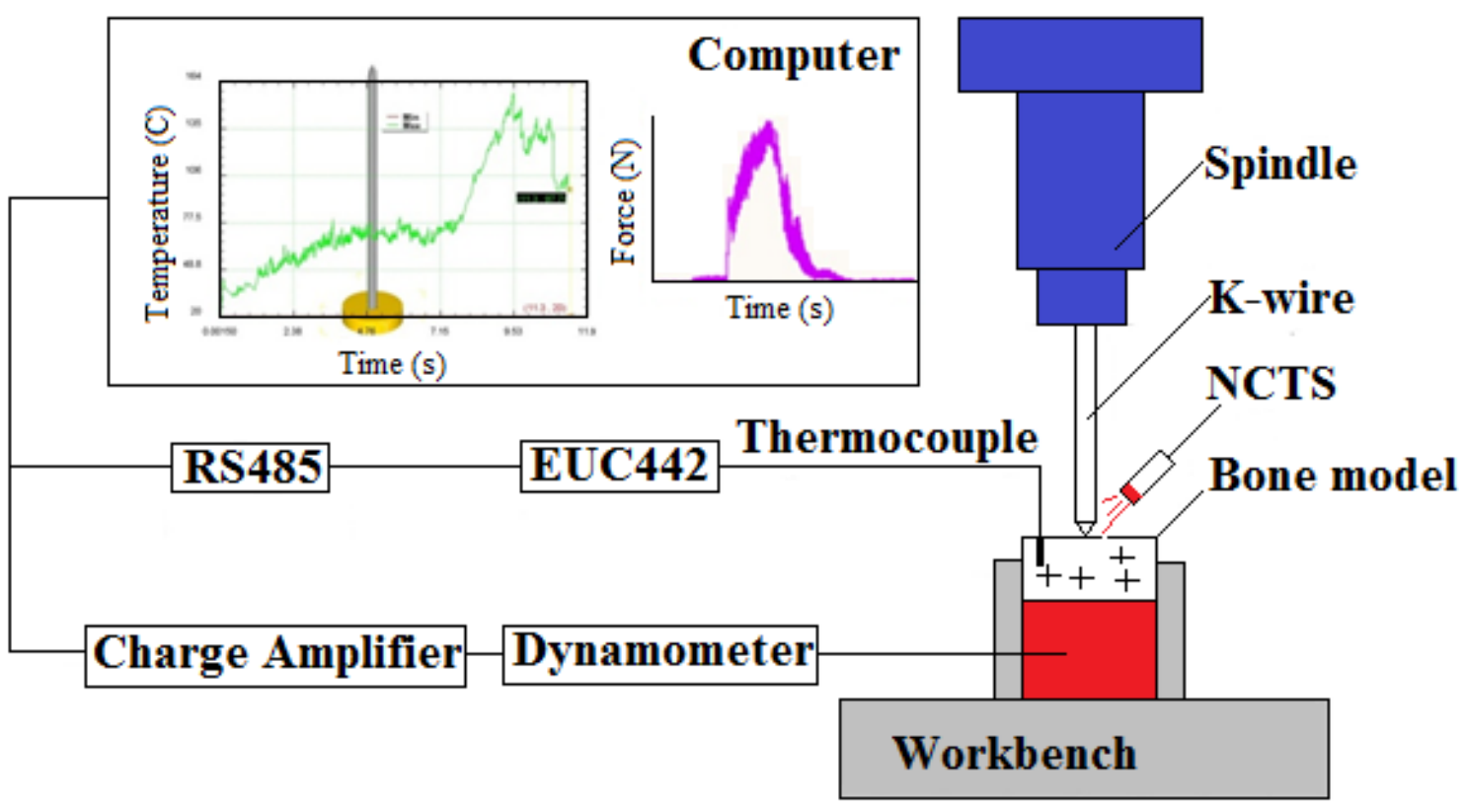

Figure 4. Schematic circuit view of bone model drilling test unit.

tion, the simple cylindrical bone model was fixed from lateral surfaces and bottom. In the drill bit model, different spindle speeds around its axis and constant feed rate in the direction of a drilling axis $(Z)$ are given in Fig. 5b. The contact algorithm between drill bit and bone model was identified as master and slave in the software, where the master element was drill bit and slave element was bone model, respectively. The friction equation of Coulomb was preferred for the friction model of these two elements. Coulomb friction model may be used in low cutting speed. However, high temperatures and high normal stresses occur in high cutting speeds (Arrazola et al., 2008). The friction coefficient between Kwire and chip during the orthogonal cutting process (Fig. 6) is calculated with Eqs. (28) and (29) (Özel, 2006). The forces in Eqs. (28) and (29), respectively, are the main cutting force $F_{\mathrm{c}}$ occurring on the rake face and the thrust force $F_{\mathrm{t}}$. These forces are measured by using a dynamometer. These forces are, respectively, the shear force $\left(F_{\mathrm{S}}\right)$ occurring on the shear plane and the vertical force to it $\left(N_{s}\right)$. Lastly, $(F)$, which occurs on the friction plane, and $(N)$, which is vertical force to it, are calculated by using $\left(F_{\mathrm{c}}\right)$ and $\left(F_{\mathrm{t}}\right)$, where $\mu$ is the friction coefficient, $\beta$ the friction angle, and $\gamma$ the rake angle as seen in Fig. 6.

$\mu=\tan \beta=\frac{F}{N}$

$\mu=\frac{F_{\mathrm{t}}+F_{\mathrm{c}} \tan \gamma}{F_{\mathrm{c}}-F_{\mathrm{t}} \tan \gamma}$

Such a friction model is preferred for low cutting speeds in general. In the simulation study, in which both spindle speeds were used, the drilling process parameters calculated by soft-

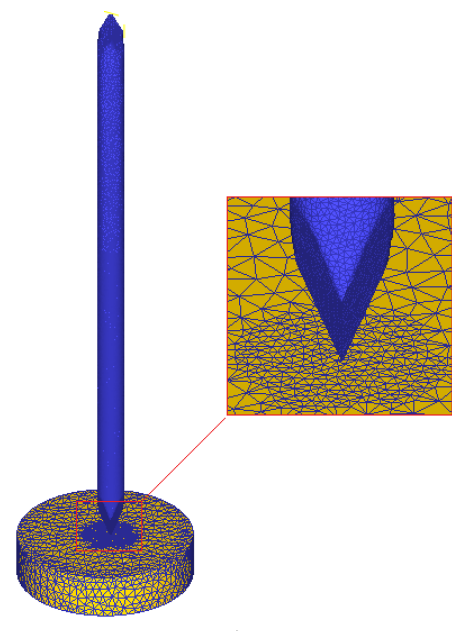

a)

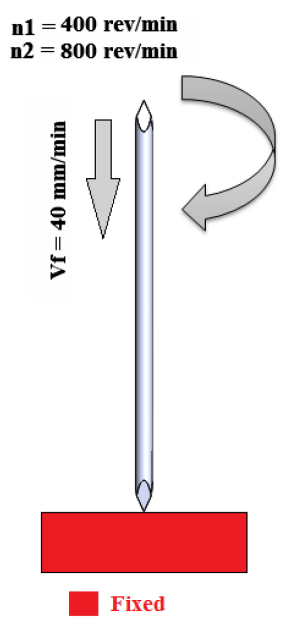

b)
Figure 5. The structure of (a) bone model and K-wire as well as (b) boundary conditions.

ware developed are given in Table 1 . The heat transfer coefficients were calculated for each $1 \mathrm{~mm}$ of the drilling process (Fig. 7).

\subsection{Material model}

A material model including mechanical and thermal properties of the bone model and K-wire was defined in the simulation. The stainless steel (AISI 304) material properties were selected for the K-wire. The mechanical and thermal properties of the AISI 304 and bone model materials are given in Table 2. The mechanical properties of the materials must 


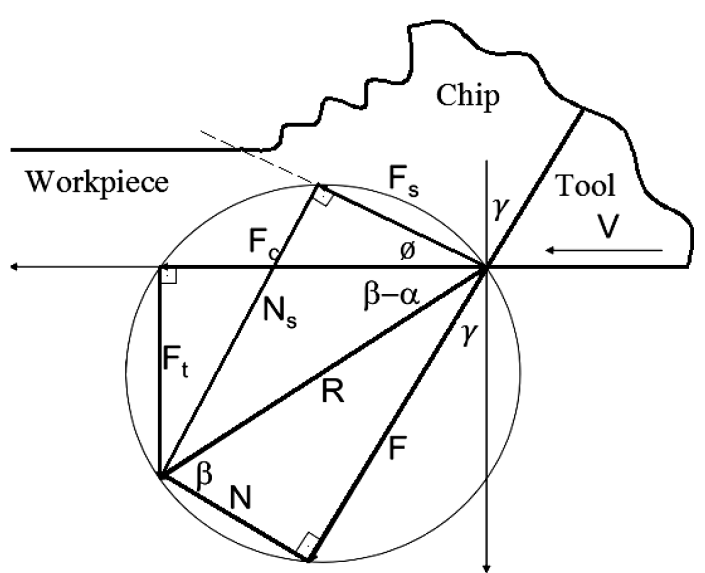

Figure 6. Two-dimensional (2-D) forces system in drilling operations (Merchant's force circle).

have been exactly known since the drilling processes were performed at high temperatures and strain rates. Therefore, the flow stress curve of the bone model material was used. Due to the lack of flow stress curves for all materials, tensile test data were used carefully for the different temperatures and strain rates. The flow stress curves (McElhaney and Byars, 1965) were used in the simulation for the bone model material model defined as a function of strain, strain rate, and temperature as can be seen in Fig. 8. The flow stress $\bar{\sigma}$ in Eq. (30) was selected to exhibit true material behavior as a function of the effective plastic strain $(\bar{\varepsilon})$, effective strain rate $(\dot{\bar{\varepsilon}})$, and temperature $(T)$.

$\bar{\sigma}=(\bar{\varepsilon}, \dot{\bar{\varepsilon}}, T)$

\section{Results}

Bone model drilling experiments were performed using Kwire for two spindle speed values $(400-800 \mathrm{rpm})$ and bone model and K-wire temperatures were obtained separately. Moreover, numerical analyses were performed based on the FEM, using DEFORM-3D software. The main cutting force and thrust force were measured both experimental and via FEM. These two features are very important for drilling operations. Especially, the temperature value occurring in bone during the drilling process is very important in terms of necrosis. If this temperature value exceeds $47^{\circ} \mathrm{C}$, irreversible damage may occur in bone and surrounding tissues. The heat transfer coefficient values were calculated using these temperature values via developed software for drilling simulation. Finally, experimental results and FEA results were compared.

As it can be seen in Fig. 9, it has been observed that the main cutting force and thrust force reduced with increasing spindle speed as a result of experimental and drilling simu-
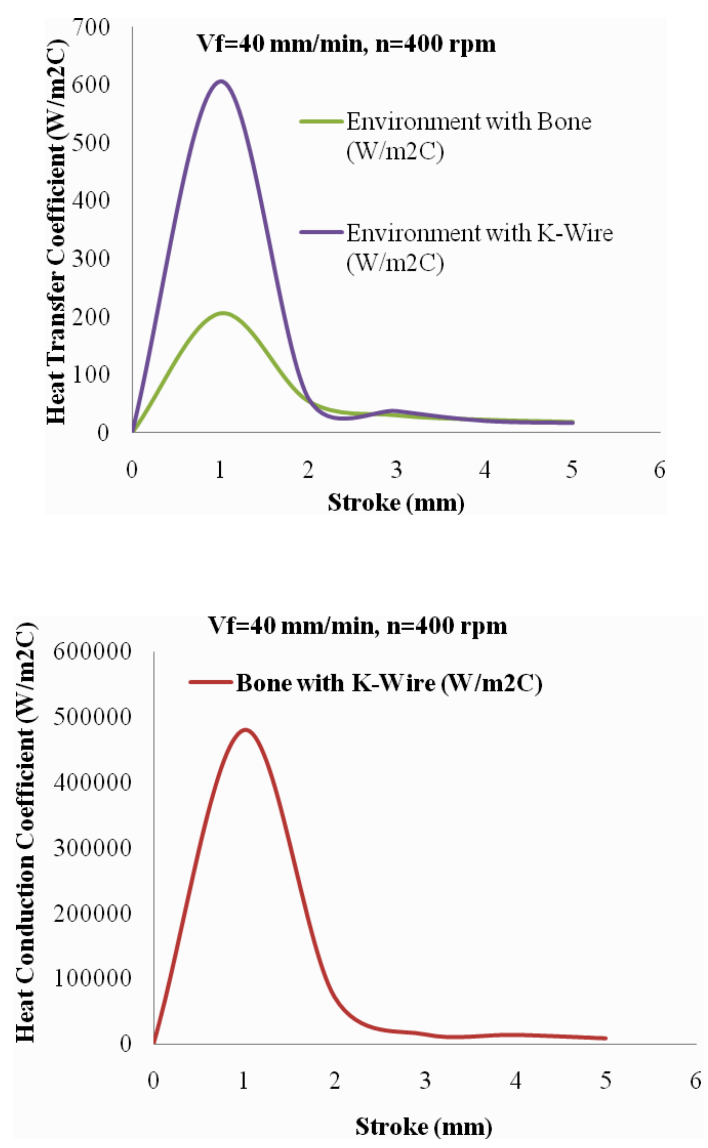

Figure 7. The heat transfer coefficients for each $1 \mathrm{~mm}$ of the drilling process.

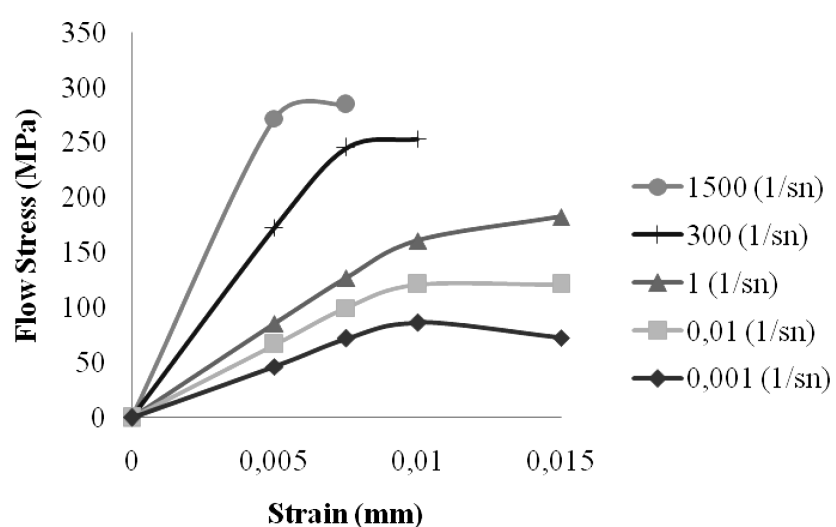

Figure 8. Flow stress of bone (McElhaney and Byars, 1965).

lations of the bone model drilling processes using a $\mathrm{K}$-wire (Fig. 9a and b). Conversely, the temperature values of K-wire and bone model increased as a result of the increase in spindle speed (Fig. 9c and d). In Fig. 10, the maximum temperature values occurring in bone models at the different spindle speeds were presented. 
Table 2. Mechanical and thermal properties of the drill bit and bone model materials.

\begin{tabular}{|c|c|}
\hline \multicolumn{2}{|c|}{$\begin{array}{c}\text { Drill bit material properties (AISI 304) } \\
\text { (Deform_Material_Library)(Deform_Material_Library) }\end{array}$} \\
\hline Elasticity modulus (GPa) & $20^{\circ} \mathrm{C}(210)$ \\
\hline Poisson's ratio & 0.3 \\
\hline $\begin{array}{l}\text { Thermal expansion coefficient } \\
\left(10^{-6}{ }^{\circ} \mathrm{C}^{-1}\right)\end{array}$ & $93.33^{\circ} \mathrm{C}\left(1.20 \times 10^{-5}\right)$ \\
\hline Thermal conductivity $(\mathrm{W} / \mathrm{mK})$ & $100^{\circ} \mathrm{C}(17)$ \\
\hline Heat capacity $\left(\mathrm{N} \mathrm{mm}^{-2}{ }^{\circ} \mathrm{C}\right)$ & $93.33^{\circ} \mathrm{C}(2.78)$ \\
\hline Emissivity & 0.7 \\
\hline \multicolumn{2}{|c|}{$\begin{array}{l}\text { The bone model material properties } \\
\text { (http://www.matweb.com/)(http://www.matweb.com/) }\end{array}$} \\
\hline Modulus of elasticity (GPa) & 17 \\
\hline Poisson's ratio & 0.35 \\
\hline Thermal conductivity $\left(\mathrm{W} \mathrm{mK}^{-1}\right)$ & 0.38 \\
\hline Specific heat $\left(\mathrm{J} \mathrm{kg}^{\circ} \mathrm{C}\right)$ & 1260 \\
\hline
\end{tabular}

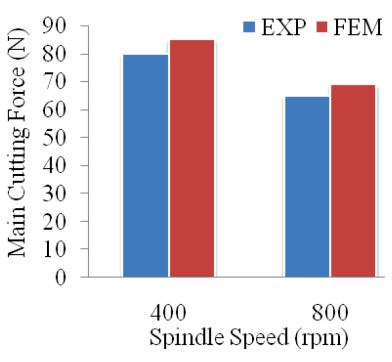

a)

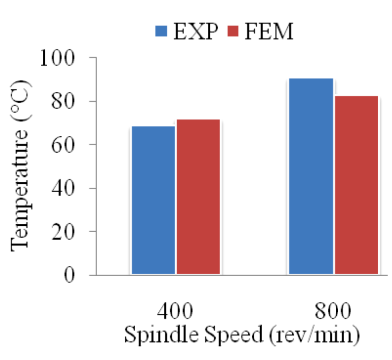

c)

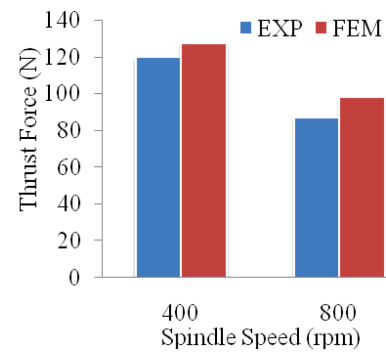

b)

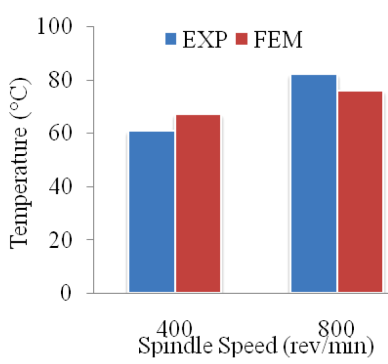

d)
Figure 9. Experimental and FEA results: (a) main cutting force, (b) thrust force, (c) bone model temperature, and (d) K-wire temperature in the bone model drilling process.

\section{Discussion}

After that bone model drilling processes were performed using K-wire, the main cutting forces, thrust force, bone models and K-wires temperature values were obtained both experimentally and via FEM. The temperature values in bone model samples and K-wire occurred above the critical temperature value $\left(47^{\circ} \mathrm{C}\right)$. This situation is not desired by sur-
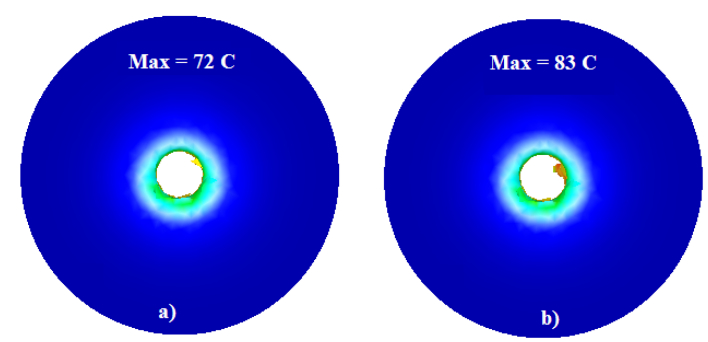

Figure 10. The maximum temperature values occurring in bone model at the different spindle speeds: (a) $400 \mathrm{rpm}$ and (b) $800 \mathrm{rpm}$.

geons too much. To prevent this temperature, there are several methods. One of them is to select the optimum cutting parameters. The other is to cool the drill bit, cutting tool or $\mathrm{K}$-wire from internal or external. This study focused on developing the software, analytic model and FEM model to calculate process parameters using drilling simulations on the bone model samples using K-wire. In studies performed by Gok et al. (2015a, b) bone temperature values were measured less at the lower spindle speed. Additionally, non-contact temperature sensor was used for measure temperature values in K-wire in this study. A more sophisticated measuring device may be used instead of this device in future studies. Additionally, in future, another study may be performed using $\mathrm{K}$-wires of a different type.

\section{Conclusions}

An analytic model and software was developed to calculate the drilling and thrust power required for chip removal in the numerical simulations of bone model drilling processes, as well as heat transfer mechanisms and coefficients between drill bit, bone model and environment, respectively. 
Computer-aided numerical simulation of the bone model drilling process was also performed using DEFORM-3D software. Based on both experimental and FEA results, the following conclusions can be obtained:

- As it can be seen in Fig. 9, it has been observed that the main cutting force and thrust force reduced with increasing spindle speed as a result of experimental and drilling simulations of the bone model drilling processes using a K-wire. Conversely, the temperature values of $\mathrm{K}$-wire and bone model increased as a result of the increase in spindle speed.

- There is a good consistency between experimental results and FEA results. This has proved the validity of the software and finite element model. Thus, this model can be used reliably in such drilling processes.

- The temperature values in bone model samples and $\mathrm{K}$-wire occurred above the critical temperature value $\left(47^{\circ} \mathrm{C}\right)$. Use of lower spindle speeds is recommended.

Edited by: J. van den Dobbelsteen

Reviewed by: S. Neseli and one anonymous referee

\section{References}

Alam, K., Mitrofanov, A. V., and Silberschmidt, V. V.: Finite element analysis of forces of plane cutting of cortical bone, Comput. Mater. Sci., 46, 738-743, 2009.

Alam, K., Mitrofanov, A. V., and Silberschmidt, V. V.: Thermal analysis of orthogonal cutting of cortical bone using finite element simulations, International Journal of Experimental and Computational Biomechanics, 1, 236-251, 2010.

Arrazola, P. J., Ugarte, D., and Domínguez, X.: A new approach for the friction identification during machining through the use of finite element modeling, Int. J. Mach. Tool. Manu., 48, 173-183, 2008.

Augustin, G., Davila, S., Mihoci, K., Udiljak, T., Vedrina, D., and Antabak, A.: Thermal osteonecrosis and bone drilling parameters revisited, Arch. Orthop. Trauma. Surg., 128, 71-77, 2008.

Basener, C. J., Mehlman, C. T., and DiPasquale, T. G.: Growth disturbance after distal femoral growth plate fractures in children: a meta-analysis, J. Orthop. Trauma., 23, 663-667, 2009.

Dahl, W. J., Silva, S., and Vanderhave, K. L.: Distal Femoral Physeal Fixation: Are Smooth Pins Really Safe?, J. Pediatr. Orthoped., 34, 134-138, doi:10.1097/BPO.0000000000000083, 2014.

Eid, A. M. and Hafez, M. A.: Traumatic injuries of the distal femoral physis. Retrospective study on 151 cases, Injury, 33, 251-255, 2002.

Eriksson, A. R,, Albrektsson, T., and Albrektsson, B.: Heat caused by drilling cortical bone. Temperature measured in vivo in patients and animals, Acta. Orthop. Scand., 55, 629-631, 1984.
Gok, K., Buluc, L., Muezzinoglu, U., and Kisioglu, Y.: Development of a new driller system to prevent the osteonecrosis in orthopedic surgery applications, J Braz. Soc. Mech. Sci. Eng., 37, 549-558, 2015a.

Gok, K., Gok, A., and Kisioglu, Y.: Optimization of processing parameters of a developed new driller system for orthopedic surgery applications using Taguchi method, Int. J. Adv. Manuf. Technol., 76, 1437-1448, 2015 b.

Hillery, M. T. and Shuaib, I.: Temperature effects in the drilling of human and bovine bone, J. Mater. Process. Tech., 92-93, 302308, 1999.

Herring, J. A.: Lower extremity injuries, in: Tachdjian's Pediatric Orthopaedics, USA: W.B. Saunders Company, 2327-2334, 2002.

Liu, R. W., Armstrong, D. G., Levine, A. D., Gilmore, A., Thompson, G. H., and Cooperman, D. R.: An Anatomic Study of the Distal Femoral Epiphysis, J. Pediatr. Orthoped., 33, 743-749 doi:10.1097/BPO.0b013e31829d55bf, 2013.

Lombardo, S. J. and Harvey J. P. J. R.: Fractures of the distal femoral epiphyses. Factors influencing prognosis: a review of thirty-four cases, J. Bone Joint Surg., 59, 742-751, 1977.

Mann, D. C. and S, R.: Distribution of physeal and nonphyseal fractures in 2,650 long-bone fractures in children aged 0-16 years, J. Pediatr. Orthop., 10, 713-716, 1990.

McElhaney, J. and Byars, E. F.: Dynamic response of biological materials, American Society of Mechanical Engineers, New York, 150-175, 1965.

Özel, T.: The influence of friction models on finite element simulations of machining, Int. J. Mach. Tool Manu., 46, 518-530, 2006.

Peterson, H. A., Madhok, R., Benson, J. T., Ilstrup, D. M., and Melton, L. J. 3rd: Physeal fractures: Part 1, Epidemiology in Olmsted County, Minnesota, 1979-1988, J. Pediatr. Orthop., 14, 423-430, 1994.

Salter, R. B. and Harris, W. R.: Injuries Involving the Epiphyseal Plate, 587-622, 1963.

Sezek, S., Aksakal, B., and Karaca, F.: Influence of drill parameters on bone temperature and necrosis: A FEM modelling and in vitro experiments, Comput. Mater. Sci., 60, 13-18, 2012.

Ulutan, D., Lazoglu, I., and Dinc, C.: Three-dimensional temperature predictions in machining processes using finite difference method, J. Mater. Process. Tech., 209, 1111-1121, 2009.

Wheeless' Textbook of Orthopaedics, 2014.

Yuan-Kun, T., Hsun-Heng, T., Li-Wen, C., Ching-Chieh, H., YungChuan, C., and Li-Chiang, L.: Finite element simulation of drill bit and bone thermal contact during drilling, Shanghai, China, 16-18 May, 1268-1271, 2008.

Yuan-Kun, T., You-Yao, H., and Yung-Chuan, C.: Finite element modeling of kirschner pin and bone thermalcontact during drilling, Life Sci. J., 6, 23-27, 2009.

Yuan-Kun, T., Wei-Hua, L., Li-Wen, C., Ji-Sih, C., and YungChuan, C.: The effects of drilling parameters on bone temperatures: a finite element simulation, Wuhan, China, 10-12 May, $1-4,2011$.

Zionts, L. E.: Fractures and dislocations about the knee. In: Skeletal Trauma in Children, USA: Saunders, 443-449, 2003. 